\title{
PADRÕES DE RECORRÊNCIA ENTRE RESUMOS E INTRODUÇÕES DE ARTIGOS CIENTÍFICOS DE ALUNOS DE GRADUAÇÃO
}

\author{
RECURRENCE PATTERNS BETWEEN ABSTRACTS AND \\ INTRODUCTIONS IN RESEARCH ARTICLES BY \\ UNDERGRADUATE STUDENTS
}

Benedito Gomes Bezerra (UNICAP/UPE) ${ }^{1}$ Kamyla Pradines Guimarães (UNICAP) ${ }^{2}$

\section{RESUMO}

Nas práticas de escrita de um curso de graduação, o estudante precisa lidar com gêneros específicos do ambiente universitário, entre os quais se destaca o artigo científico e, nele, o resumo e a introdução como portas de entrada ao texto principal. É de se esperar que haja uma relação de continuidade entre o resumo e a introdução do artigo, do ponto de vista das informações incluídas e de sua distribuição nos respectivos movimentos retóricos. Diante disso, o objetivo deste trabalho é analisar comparativamente, à luz da teoria de gêneros swalesiana, a distribuição das informações (movimentos e passos ou estratégias retóricas) entre o resumo e a introdução do artigo científico. Para tanto, foram selecionados 10 artigos produzidos por estudantes do curso de Letras, que foram submetidos à análise de sua organização retórica. Os resultados indicam que os textos mantêm um padrão de parcial continuidade entre o resumo e a introdução, com descontinuidades também notáveis. Do ponto de vista dos letramentos, concluímos que a produção desses gêneros acadêmicos ainda representa uma tarefa significativamente complexa para o graduando.

PALAVRAS-CHAVE: Artigo científico; Resumo; Introdução; Organização retórica; letramentos.

\begin{abstract}
In the undergraduate writing practices, the students need to deal with specific genres of the academic context, among which the scientific article stands out and, in it, the abstract and the introduction as doorsteps for the main text. It is expected that there will be a continuity pattern between the abstract and the introduction in the article, from the point of view of the information included and its distribution in the respective rhetorical movements. The aim of this paper is to comparatively analyze, based on Swalesian genre theory, the distribution of information (rhetorical moves and steps/strategies) between the abstract and the introduction of the scientific article. To this purpose, 10 articles produced by students of a Letters undergraduate course were selected and submitted to the analysis of their rhetorical organization. The results indicate that the texts present a partial continuity pattern between the abstract and the introduction, with also noticeable discontinuities. From the literacies point of view, we concluded that the production of these academic genres still represents a significantly complex task for the undergraduate.
\end{abstract}

KEYWORDS: Research article; Abstract; Introduction; Rhetorical organization; literacies.

\footnotetext{
1 Doutor em Letras/Linguística pela Universidade Federal de Pernambuco (UFPE). E-mail: beneditobezerra@gmail.com.

2 Mestranda em Ciências da Linguagem pela Universidade Católica de Pernambuco (UNICAP). E-mail: kamyla.pradines2018@gmail.com.
} 


\section{INTRODUÇÃO}

O aluno que adentra um curso de graduação universitária se depara com uma realidade acadêmica constituída por práticas distintas de leitura e escrita, que se efetivam em eventos de letramentos bastante específicos. Partindo desse pressuposto e tendo em vista que o artigo científico é um gênero de grande notoriedade na comunidade científica, podemos afirmar que estar familiarizado com ele é essencial para se obter êxito em um cenário acadêmico de "publique ou pereça!" (MOTTA-ROTH; HENDGES, 2010, p. 13). Além do mais, para aqueles que almejam uma carreira como pesquisador, a publicação de resultados de pesquisa através de artigos científicos em periódicos é uma condição de prestígio, o que torna o artigo uma via de comunicação imprescindível para quem pretende divulgar os resultados dos estudos realizados. Como salientado por Motta-Roth e Hendges (2010, p. 66),

a atividade de pesquisa está essencialmente ligada ao meio universitário, onde professores e alunos desenvolvem estudos avançados e pesquisas que, mais tarde, se tornarão públicas por meio de apresentações em congressos, mas principalmente, por meio da publicação de artigos.

Contudo, apesar da necessidade de se dominar a prática de produção do artigo, percebese que nem sempre os estudantes estão suficientemente familiarizados com ele, pois "nem sempre se reserva espaço e tempo específicos para o seu ensino no currículo dos diversos cursos" de graduação (BEZERRA, 2012, p. 248).

O primeiro contato do leitor com o artigo científico se dá pelo resumo (ou abstract, na sua versão em inglês). Dessa maneira, o resumo precisa trazer as informações primordiais do texto fonte, convencer o leitor a respeito da relevância da pesquisa e contribuir para determinar, de maneira prévia, se o artigo será ou não útil para o pesquisador interessado. Para Motta-Roth e Hendges (2010, p. 152), “o abstract resume as informações do texto mais longo, permitindo que os leitores tenham acesso mais rápido ao conteúdo desse texto. Em outras palavras, o abstract é um texto breve que encapsula a essência do artigo que se seguirá”.

Posteriormente ao abstract, no plano sequencial do texto, a seção de introdução também é responsável por seduzir o leitor causando uma impressão inicial positiva. É nela que os autores relatam os objetivos e também podem argumentar sobre a relevância do estudo. Conforme salientam Ritti-Dias e Bezerra (2013, p. 166), "essa percepção da importância da introdução para o sucesso do artigo já orientava o trabalho de Swales (1990)".

Partindo dessas considerações, o objetivo deste trabalho foi analisar os movimentos e estratégias ou passos retóricos característicos de introduções e resumos de artigos científicos do ponto de vista de quais informações são inseridas em uma ou em outra parte do texto, e até que ponto há uma coerência ou continuidade entre elas. Esse é um aspecto particularmente inovador no estudo, uma vez que pesquisadores anteriores, tais como Swales (1990), Biasi-Rodrigues (1998) e Ritti-Dias e Bezerra (2013), usualmente se concentraram na análise de resumos e introduções separadamente.

Para alcançar o objetivo proposto, o trabalho está organizado em quatro tópicos. No primeiro, discorremos sobre a noção de letramentos acadêmicos sob o viés dos gêneros textuais, vistos como necessariamente pautados em práticas sociais e discursivas. Em seguida, dedicamos dois tópicos para explicitar os modelos retóricos adotados para análise do corpus. E, por fim, analisamos o corpus, com especial atenção para a correlação entre resumo e introdução, buscando ainda verificar quais são as estruturas retóricas mais recorrentes em ambas as partes.

\section{Procedimentos metodológicos}

A análise se concentrou em um corpus de 10 (dez) artigos científicos produzidos, nos anos de 2017 e 2018, por estudantes do curso de Letras de uma universidade comunitária do 
Estado de Pernambuco. Adotamos como critério de seleção a diversidade de autores e orientadores no que diz respeito à produção dos textos coletados. Alguns desses textos foram produzidos com a finalidade de obter avaliação em disciplinas do curso de Letras, e outros tiveram caráter independente de sala de aula, tendo sido motivados pela participação dos alunos em projetos de Iniciação Científica.

Em nossos esforços para coletar o corpus, consultamos vários alunos de períodos diversos se eles já haviam produzido um texto do gênero artigo científico. Uma boa parte deles relatou que já produziu um artigo em algum momento do curso e se disponibilizou a enviá-lo aos pesquisadores sob a condição da não exposição do nome do autor. Os textos foram enviados pelos alunos através de e-mail, sendo posteriormente impressos para análise. Apesar do grande número de textos recebidos, poucos deles foram julgados como se enquadrando no gênero requerido. Em termos mais específicos, percebemos que os textos recebidos se configuravam como resumos, relatórios finais e parciais de IC, resenhas e relatórios de estágio, o que nos fez observar que os estudantes por vezes sequer percebem as especificidades dos gêneros que circulam na universidade no âmbito do curso de graduação. Diante do enorme desconhecimento das convenções acerca do gênero solicitado, tivemos que explicar resumidamente as características do artigo científico para obtermos textos que se enquadrassem no gênero desejado.

Uma vez reunido o corpus, a proposta de análise consistiu em verificar a organização retórica de resumos e de introduções de artigos científicos para em um segundo momento examinar continuidades e descontinuidades informacionais e retóricas entre os textos. Para a análise dos dados foi utilizado, no que tange às introduções, o Modelo CARS (Create a Research Space) conforme proposto por Swales (1990) e modificado pelo autor em obra posterior (SWALES, 2004). O modelo, considerado pioneiro no campo dos estudos sociorretóricos, foi revisitado por Biasi-Rodrigues, Hemais e Araújo (2005) e Motta-Roth e Hendges (2010), cujas contribuições também auxiliaram esta pesquisa.

Quanto aos resumos, toda a análise foi realizada a partir da proposta de Oliveira (2017), cujo modelo, de acordo com as palavras do próprio autor:

Enquadra as ocorrências das estratégias retóricas mais enfáticas e utilizadas por uma grande maioria de estudantes, professores e pesquisadores da área de Letras/Linguística. Para isso, observamos uma possibilidade mais viável, uma melhor comodidade na aplicação desse modelo em estudos futuros (OLIVEIRA, 2017, p. 119).

Todos os artigos analisados se enquadram na categoria de artigos empíricos, que têm por objetivo "apresentar e discutir dados sobre determinado problema dentro de uma área de conhecimento específica e fazer interpretações na forma de resultados de pesquisa" (MOTTAROTH; HENDGES, 2010, p. 67).

\section{Letramentos acadêmicos e gêneros textuais}

A obra de Brian Street (1984) teve uma importância decisiva para uma virada paradigmática no campo dos estudos de letramentos, levando esses estudos a assumirem um caráter muito mais social e cultural a respeito das práticas de leitura e escrita. Foi nesse contexto que teóricos passaram a evidenciar a multiplicidade das práticas letradas, consolidando a vertente denominada de Novos Estudos do Letramento $\left(\mathrm{NEL}^{3}\right)$ no Reino Unido.

No bojo dessa mudança, Street (1984) propôs dois modelos descritivos que mais adiante seriam decisivos para o surgimento da abordagem dos letramentos acadêmicos (ACLITS, do inglês Academic Literacies), quais sejam: o modelo ideológico e o modelo autônomo. O primeiro pressupõe que o indivíduo seja capaz de se desenvolver integralmente em uma sociedade letrada se tão somente adquirir as habilidades individuais de ler e escrever. O segundo modelo aborda o

${ }^{3}$ Em inglês, New Literacy Studies (NLS). 
caráter social que envolve qualquer evento de letramento. Marcuschi (2001) sugeriu que o ideal seria mesclar elementos de ambos os modelos, para evitar que tratemos o letramento ora como um fenômeno estritamente linguístico, ora como um fenômeno estritamente social. Ressalte-se que, para Street (1984), igualmente, a opção pelo modelo ideológico não obscurece o valor das habilidades linguísticas contempladas pelo modelo autônomo, mas permite a incorporação de aspectos fundamentais para a compreensão da escrita e da leitura como práticas sociais.

Nessa linha, no Brasil, o termo letramento foi utilizado para designar os usos da escrita na vida social, distinguindo-os da alfabetização como mera habilidade de codificar e decodificar. Quanto à corrente dos estudos de letramentos acadêmicos, entre os trabalhos que inauguraram o campo no país, podemos mencionar Fischer (2007), seguido por outros estudos tais como Marinho (2010), Fiad (2011; 2015) e Oliveira (2017). As obras seminais de Lea e Street (1998; 2006) muito contribuíram para esses estudos. A abordagem dos letramentos acadêmicos propicia um olhar crítico para a complexidade das práticas de leitura e escrita específicas do ambiente universitário, como no caso deste estudo.

Por sua vez, os gêneros textuais ocupam lugar central quando falamos em práticas de escrita e leitura na universidade e, por assim dizer, em todos os contextos, porque não se pode pensar em um contexto de utilização de tais práticas (especialmente da escrita) como função social sem que a elas esteja ligado algum gênero textual. Também, conforme Johns (1997, p. 2) "o termo letramento leva em consideração as influências sociais, históricas e cognitivas que pesam sobre leitores e escritores em sua tentativa de processar e produzir textos". Nesse sentido, conforme salienta Bezerra (2012, p. 252), enfocar letramentos em conexão com gêneros implica lidar com saberes compartilhados sobre nomes de gêneros, propósitos comunicativos, papéis de leitores e escritores, contextos, convenções formais, conteúdos, registros, valores culturais e intertextualidade.

Diversos estudos já demonstraram que não é fácil para os estudantes de graduação se apropriarem de novas práticas de leitura e escrita, uma vez que se trata de "práticas complexas que envolvem a orientação do aluno para o desenvolvimento de múltiplas competências, numa complexa inter-relação entre aspectos linguísticos, cognitivos e socioculturais" (BEZERRA, 2012, p. 247). Segundo argumenta o autor, nenhum aluno aprende automaticamente a lidar com os gêneros textuais específicos da academia, e mesmo assim não há um investimento significativo no seu ensino, ainda que o domínio de tais gêneros seja considerado essencial para a obtenção de êxito na universidade.

Podemos asseverar que os gêneros textuais são caminhos que, quando trilhados, nos levam a locais bastantes específicos. Por exemplo, ninguém escreve requerimentos, chats, resenhas acadêmicas ou e-mails sem que tenha um propósito claramente definido. E a essa condição ou habilidade de usar os gêneros no contexto social com finalidades bem definidas e organizar ações através de textos é que se dá o nome de letramento.

\section{$3 \mathrm{O}$ modelo CARS para introduções de artigos científicos}

O Modelo CARS (SWALES, 1990) surgiu originalmente como resultado do trabalho de John Swales com introduções de artigos de pesquisa das áreas de psicologia, física e educação, tendo sido adaptado posteriormente para a análise de outros gêneros textuais de diversas áreas disciplinares e domínios discursivos. A saber, esse modelo possibilitou, "além de um trabalho investigativo, também um trabalho de caráter pedagógico" (RITTI-DIAS; BEZERRA, 2013, p. 169), uma vez que também tem sido utilizado para orientar o ensino da escrita do artigo científico e de outros gêneros acadêmicos. Neste trabalho, adotamos uma mescla do modelo original com uma versão posterior (SWALES, 2004) para investigar as estratégias que os graduandos em Letras usam para distribuir as informações nas seções de introdução de artigos científicos. 
O modelo CARS é composto por três unidades argumentativas funcionais denominadas "movimentos retóricos" (moves), realizadas por meio de estratégias retóricas denominadas "passos" (steps), que se alternam entre opcionais e obrigatórios. Conforme ressaltam Motta-Roth e Hendges (2010, p. 83), "cada uma dessas etapas do texto é interpretada como um movimento em um jogo de xadrez, cujo objetivo último é convencer o leitor da importância do artigo e, assim, persuadi-lo a seguir lendo o artigo até o fim". No Quadro 1, detalhamos, para uma visão geral dos resultados, o Modelo CARS e as ocorrências de cada passo nas introduções que analisamos. Para nomear os movimentos retóricos, mantivemos o termo original move, por uma questão de brevidade; os steps são, por sua vez, referidos como "passos". Um dos passos adicionais sugeridos por Swales (2004), o único verificado no corpus, está destacado no quadro entre colchetes, marcando-se dessa forma seu caráter de acréscimo ou modificação da versão clássica do modelo CARS, mais comumente utilizado nas análises de movimentos retóricos em gêneros. Segue-se uma discussão detalhada dos resultados no tópico 5 deste trabalho.

Quadro 1: Introduções de artigos analisados segundo o modelo CARS MODELO CARS (SWALES, 1990; 2004) INTRODUÇÕES DE ARTIGOS CIENTÍFICOS

\begin{tabular}{|c|c|c|c|c|c|c|c|c|c|c|}
\hline MOVE 1: ESTABELECENDO UM TERRITÓRIO & C1 & $\mathrm{C} 2$ & C3 & C4 & C5 & C6 & C7 & C8 & C9 & C10 \\
\hline Passo 1: Alegando centralidade e/ou & $\mathbf{X}$ & & & & & & & & & \\
\hline Passo 2: Fazendo generalizações sobre o tópico e/ou & $\mathbf{X}$ & $\mathbf{X}$ & $\mathbf{X}$ & $\mathbf{X}$ & $\mathbf{X}$ & & $\mathbf{X}$ & $\mathbf{X}$ & $\mathbf{X}$ & $\mathbf{X}$ \\
\hline Passo 3: Resenhando pesquisas anteriores & $\mathbf{X}$ & & $\mathbf{X}$ & $\mathbf{X}$ & $\mathbf{X}$ & & & & & \\
\hline \multicolumn{11}{|l|}{ MOVE 2: ESTABELECENDO UM NICHO } \\
\hline Passo 1A: Contra-argumentando ou & $\mathbf{X}$ & & & & & $\mathbf{X}$ & & & & \\
\hline Passo 1B: Indicando uma lacuna ou & & & & & & $\mathbf{X}$ & & & & \\
\hline Passo 1C: Levantando questionamentos ou & & & $\mathbf{X}$ & $\mathbf{X}$ & & & & & & \\
\hline Passo 1D: Continuando uma tradição & $\mathbf{X}$ & & $\mathbf{X}$ & & & $\mathbf{X}$ & $\mathbf{X}$ & $\mathbf{X}$ & $\mathbf{X}$ & $\mathbf{X}$ \\
\hline \multicolumn{11}{|l|}{ MOVE 3: OCUPANDO UM NICHO } \\
\hline Passo 1A: Esboçando os propósitos (objetivos) ou & $\mathbf{X}$ & $\mathbf{X}$ & $\mathbf{X}$ & & $\mathbf{X}$ & & $\mathbf{X}$ & $\mathbf{X}$ & $\mathbf{X}$ & \\
\hline \multicolumn{11}{|l|}{ Passo 1B: Anunciando a presente pesquisa } \\
\hline Passo 2- Anunciando os principais achados & & & $\mathbf{X}$ & & & & & & & \\
\hline \multicolumn{11}{|l|}{ Passo 3: Indicando a estrutura do artigo } \\
\hline [Passo 4: Resumindo a metodologia - opcional] & $\mathbf{X}$ & $\mathbf{X}$ & $\mathbf{X}$ & $\mathbf{X}$ & & & & & $\mathbf{X}$ & \\
\hline
\end{tabular}

Fonte: Elaboração dos autores a partir de Swales (1990; 2004)

\section{Adaptação do modelo CARS para a análise de resumos (OLIVEIRA, 2017)}

Em geral, o resumo/abstract atende a dois propósitos comunicativos distintos. O primeiro diz respeito ao texto produzido com o intuito de convencer uma comissão avaliadora a aceitar o trabalho do pesquisador em eventos científicos. Esse resumo, então, antecipa o conteúdo da pesquisa a ser apresentada no evento e é intitulado como resumo de comunicação. Já a segunda forma de publicação é aquela em que o resumo acompanha um outro texto acadêmico, e a sua função é sintetizar o texto fonte, indicando ao leitor se o trabalho lhe será útil. Segundo Motta-Roth e Hendges,

Especificamente no caso de artigo acadêmico, o abstract tem o objetivo de sumarizar, indicar e predizer, em um parágrafo curto, o conteúdo e a estrutura do texto integral que segue. Funcionando como uma fonte de informação precisa e completa, abstracts ajudam os pesquisadores a ter acesso rápido e eficiente ao crescente volume de publicações científicas (2010, p. 152).

O modelo formulado por Oliveira (2017), que utilizamos em nossas análises, permite investigar os movimentos retóricos presentes em ambas as modalidades de resumos. Essa versatilidade se dá porque o autor mesclou em seu modelo o roteiro desenvolvido por Bhatia 
(1993), que atendia aos resumos de comunicação, e o roteiro de autoria de Swales e Feak (2010), que atendia aos resumos de artigos científicos. O modelo em questão ficou composto por cinco movimentos ou unidades retóricas (moves) que são preenchidas por treze subunidades retóricas, equivalentes aos passos (steps) de Swales (1990). Para que as ocorrências de cada move fossem consideradas, considerou-se necessário que o autor empregasse pelo menos uma das subunidades, de forma que ele faça sua escolha "de acordo com a proeminência que quer dar a certos aspectos das informações nas respectivas unidades" (BIASI-RODRIGUES, 2009, p. 60). Trazemos abaixo a transcrição completa do modelo de Oliveira (2017) e as ocorrências de todos os passos ou subunidades retóricas nos resumos analisados. Conservando a terminologia adotada pelo autor, nomeamos os movimentos ou unidades retóricas como moves e os passos como "estratégias retóricas", abreviadas ER. A discussão desses resultados também se segue no tópico 5 , em conexão com a análise das introduções.

Quadro 2: Resumos de artigos segundo Oliveira (2017)

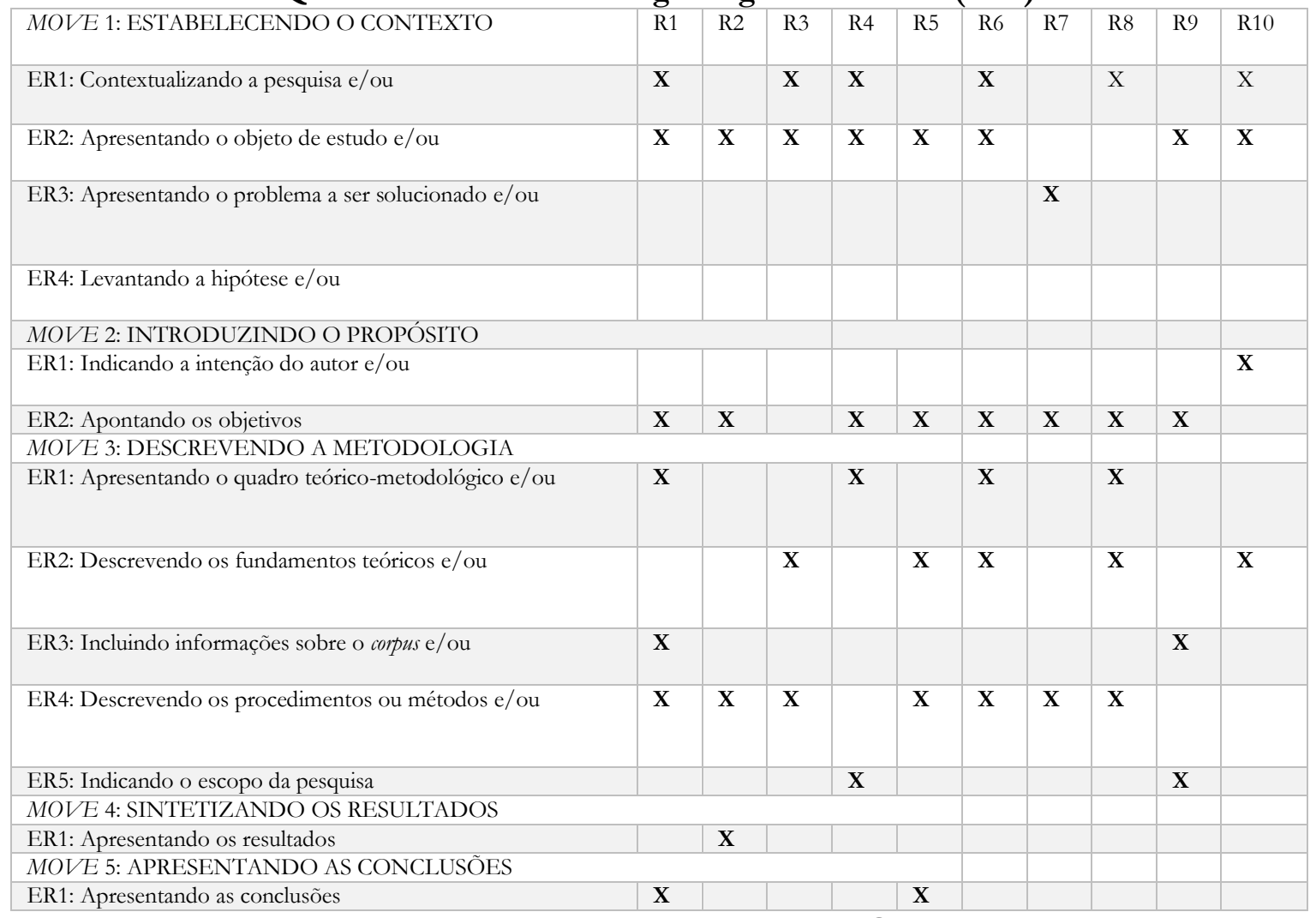

Fonte: Elaboração dos autores a partir de Oliveira (2017)

\section{$5 \mathrm{O}$ que mostram os resumos e as introduções}

O resumo e a introdução de artigos científicos diferem quanto à organização retórica e características estruturais, uma vez que ambos têm propósitos distintos e são produzidos sob circunstâncias distintas. Entretanto, eles apresentam algumas similaridades, a exemplo do caráter introdutório e apelativo de ambos no que diz respeito a chamar atenção para a relevância do estudo. Certamente há na estrutura retórica tanto do resumo quanto da introdução do artigo informações que se assemelham quanto a sua funcionalidade. São essas informações que, de acordo com os modelos adotados para a análise, mapeamos a fim de saber em quais partes do texto (resumo ou introdução) elas costumam ser inseridas, se há uma continuidade e clareza quanto a sua distribuição e a que propósito comunicativo servem as estratégias empregadas pelos estudantes-autores em detrimento de outras. 
Ao analisarmos o total de ocorrências dos movimentos e passos (ou unidades e estratégias retóricas) do resumo e da introdução, os resultados obtidos mostraram que os autores fazem generalizações acerca da pesquisa e do objeto de estudo em ambas as partes do artigo. $\mathrm{Na}$ totalidade dos resumos coletados e analisados, os autores recorreram, no Movimento 1 (Estabelecendo o contexto), às estratégias retóricas ER1 (Contextualizando a pesquisa), ER2 (Apresentando o objeto de estudo) e ER3 (Apresentando o problema a ser solucionado), desprezando a ER4 (Levantando hipóteses). Foi possível observar que, nesse movimento retórico, a estratégia mais recorrente foi a ER2 (Apresentando o objeto de estudo), a qual esteve presente em 08 (oito) resumos.

\section{Exemplo 1: Move 1, ER2, Resumo 6}

Este estudo visa apresentar o tema da variação linguística e o ensino do português, tento como principal abordagem $[\ldots]$

Exemplo 2: Move 1, ER2, Resumo 10

O presente artigo aborda dois aspectos: a submissão para agradar ao companheiro e a perda da identidade [...]

Em contrapartida, a ER3 (Apresentando um problema a ser solucionado) foi realizada por apenas um autor. Tal estratégia seria uma forma de estabelecer um espaço ou "nicho" para o estudo, a partir de lacunas em pesquisas anteriores que serão preenchidas pelo estudo. Desse modo, a não utilização dessa estratégia pode ser compreendida como um possível receio por parte dos estudantes em questionar uma teoria estabelecida. E ainda foi possível observar que, mesmo quando a ER3 foi empregada, o autor não deixou evidente a que teórico sua pesquisa se contrapôs, direcionando a questão para uma área disciplinar, como podemos observar no exemplo.

\section{Exemplo 3: Move 1, ER3, Resumo 7}

A partir dessa análise histórica, entendeu-se que o conceito de significado é problemático e ainda continua em aberto, levando a Semântica a uma condição de marginalização entre as ciências linguísticas, porém, isso [...]

Nas introduções, de modo semelhante, o questionamento de tradições teóricas ou pesquisas anteriores se fez de modo esporádico e vago, como no seguinte caso, em que o estudante "estabelece o território" (Movimento 1) através de referências não específicas a pesquisas anteriores.

\section{Exemplo 4: Move 1, Passo 3, Introdução 1}

Dentro dessas pesquisas, mais especificamente as que se tratam da linguagem de uma pessoa no espectro, tem se preservado uma ideia de diagnose, esquecendo-se, portanto, de entender os entrelaços peculiares que uma pessoa com esse transtorno cria com a linguagem. Essa ideia constrói certas dicotomias que são prejudiciais a uma análise $[\cdots]$

Não foi surpreendente, então, que a maioria dos estudantes se detivesse a inserir seu estudo dentro de uma linha de pesquisa já estabelecida, recorrendo, nas introduções, ao Passo 1D (Continuando uma tradição), do Movimento 2 (Estabelecendo um nicho), expediente que, aparentemente, traz uma sensação de segurança aos estudantes. Logo, a finalidade dessa estratégia retórica foi de apresentar um quadro teórico em consonância com as ideias do autor, como observado a seguir.

Exemplo 5: Move 2, Passo 1D, Introdução 3

Seguindo essa linha de pensamento, esta pesquisa busca realizar a análise do discurso de um programa televisivo, partindo da ideia de $\operatorname{Kock}^{4}$ (1997, p. 9), [...]

${ }^{4}$ A grafia, em todos os exemplos, foi mantida como originalmente produzida pelos autores. 
Ainda no que diz respeito à introdução, os autores esporadicamente empregaram a estratégia retórica representada pelo Passo 1C (Levantando questionamentos), do Movimento 2 (Estabelecendo um Nicho), na tentativa menos chamativa de enfatizar que existem problemáticas em pesquisas anteriores sem necessariamente apontar quais são tais pesquisas e a quais teóricos estão relacionadas. Esse passo foi empregado em 02 (dois) artigos, através de sentenças interrogativas bem evidentes, como podemos observar abaixo:

\section{Exemplo 6: Move 2, Passo 1C, Introdução 4}

Percebe-se que dentro das instituições de ensino muitos alunos não sentem a ausência do índio, bem como não aceitam as políticas de cotas, isso se dá devido a uma estrutura social, ou a uma romantização acerca desses primeiros nativos que precisa ser desconstruída? [...]

\section{Exemplo 7: Move 2, Passo 1C, Introdução 3}

Dessa maneira, entende-se que não restam dúvidas sobre a importância do ato de ler, então por que nossos índices são assustadoramente negativos?

Ainda no que diz respeito ao nicho em que se pretende inserir a pesquisa, foi observado que, na introdução, em dois artigos, não foi aberto o espaço para estabelecer a área da pesquisa. Dessa forma, constatamos a ausência total do Movimento 2 (Estabelecendo um nicho) nesses artigos. No entanto, percebemos que os autores buscaram, no resumo, apresentar lacunas em pesquisas já estabelecidas, através da ER3 (Apresentando o problema a ser solucionado), do Movimento 1 (Estabelecendo o contexto), indicando, assim, de maneira bastante sucinta, o nicho de pesquisa. Dessa forma, ambas as partes do texto se complementaram ao suprir as lacunas mútuas.

Notamos ainda que um dos autores, entretanto, se dedica a delinear com clareza um conjunto de objetivos do seu estudo na introdução, na tentativa de preencher um espaço que não foi claramente delimitado.

\section{Exemplo 8: Move 3, Passo 1A, Introdução 5}

O intuito deste artigo é analisar as mudanças ocasionadas pelas novas mídias no âmbito do ensino e aprendizado da língua portuguesa, dando um enfoque maior às variações linguísticas e como elas se manifestam em sala de aula.

$\mathrm{Na}$ esteira do estudo, pretende-se compreender como os vícios de linguagem - redução de palavras e erros lexicais - incorrem em afetar, diretamente ou não, a produção formal dos textos requeridos num processo de educação.

Além disso, busca-se averiguar quais os erros provenientes das novas mídias tornam-se mais frequentes nas falas cotidianas, e desta forma, como o professor pode identificá-los e dirimi-los, seja utilizando as metodologias clássicas, seja utilizando as ferramentas disponíveis no contexto atual.

Objetiva-se, também, realizar um breve estudo de campo, no qual, aprioristicamente, entrevistaremos um professor do ensino fundamental II, para, em seguida, depreender na pratica a influência desses novos agentes na esfera educacional.

De modo semelhante, o autor da introdução 5 já havia pontuado claramente o objetivo de seu trabalho no resumo, ainda que, a rigor, o objetivo explicitado no resumo não contemple os desdobramentos colocados na introdução, como se pode verificar no exemplo 9 .

\section{Exemplo 9: Move 1, ER3, Resumo 5}

O foco deste trabalho é investigar se a utilização constante das redes sociais no dia a dia dos estudantes tem influenciado, de alguma forma, a produção dos textos que são solicitados pelo professor de português em sala de aula.

Voltando à introdução, os estudantes também recorreram frequentemente à estratégia retórica representada pelo Movimento 1 (Estabelecendo um território), Passo 2 (Fazendo generalizações sobre o tópico), o qual esteve presente em 09 (nove) artigos. A forte ocorrência dessa estratégia e consequentemente do Movimento 1 (Estabelecendo um território), em que ela está inserida, "explica-se pela importância estratégica de se procurar argumentar e convencer o leitor sobre a relevância do trabalho" (RITTI-DIAS; BEZERRA, 2013, p. 174). Quanto aos 
resumos, apontar a importância do estudo foi uma estratégia pouco recorrente, realizada a partir da ER3 (Apresentando o problema a ser solucionado) do Movimento 1 (Estabelecendo o contexto).

\section{Exemplo 10: Move 1, Passo 2, Introdução 7}

Homens têm grande participações na sociedade, quando se fala desse espaço que eles ocupam não é apenas em quantidade, mas, também em vantagens, consequência de uma cultura machista implantada na história da sociedade ao longo dos anos.

\section{Exemplo 11: Move 1, Passo 2, Introdução 5}

Nas escolas o desenvolvimento da escrita e produção textual é bem superficial, além de não explorar as variantes linguísticas existentes em nossa língua, o que já traz como proposta os PCN's.

Voltando à indicação dos objetivos da pesquisa, foi observado que os estudantes-autores recorreram a estratégias retóricas similares em ambas as partes do texto. Em 07 (sete) introduções, os autores realizaram o Passo 1A (Esboçando propósitos), do Movimento 3 (Ocupando o Nicho). Já nos resumos foram encontradas 08 (oito) ocorrências da ER2 (Apontando os objetivos), do Movimento 2 (Introduzindo o propósito).

\section{Exemplo 12: Move 3, Passo 1A, Introdução 7}

O intuito deste artigo é analisar as mudanças ocasionadas pelas novas mídias no âmbito do ensino e aprendizado da língua portuguesa, dando um enfoque maior às variações linguísticas [...]

\section{Exemplo 13: Move 3, Passo 1A, Introdução 9}

A partir das ideias lançadas por Kock sobre a teoria da Intertextualidade Temática, o trabalho pretende mostrar [...]

Em um artigo, não houve qualquer menção aos objetivos da pesquisa, havendo assim uma situação atípica, uma vez que os objetivos são sempre requeridos, como, por exemplo, quando o autor deve enviar seu resumo a uma banca avaliadora ou produzir o resumo do trabalho completo. A falta dos objetivos, por assim dizer, afetou bastante o caráter informativo do estudo, deixando também muito imprecisa a área em que a pesquisa pretendeu se inserir (seu nicho).

Observamos, em nosso corpus, que, em geral, quando indicados, os objetivos foram inseridos de forma bastante sucinta nos resumos, sendo um pouco mais ampliados nas seções de introdução. De fato, devido ao caráter restrito dos resumos, que nos artigos geralmente são um texto com no máximo 300 palavras, é quase impossível explanar amplamente certos aspectos do texto sem omitir outros.

\section{Exemplo 14: Move 2, ER2, Resumo 2}

O objetivo deste trabalho é analisar as publicações científicas nas bases de dados Lilacs, Bireme e Scielo [...]

\section{Exemplo 15: Move 3, Passo 1A, Introdução 2}

Este artigo, portanto, tem como objetivo fazer uma análise de como as bases de dados Lilacs; Bireme e Scielo são permeadas de características prosódicas peculiares [...]

No que diz respeito à metodologia, nossa análise constatou que, nos resumos, os autores explanaram os procedimentos metodológicos da pesquisa principalmente através da ER4 (Descrevendo os procedimentos ou métodos), do Movimento 3 (Descrevendo a metodologia). Também foram significativamente empregadas as ER1 (Apresentando um quadro teóricometodológico) e ER2 (Descrevendo os fundamentos teóricos), 04 (quatro) e 05 (cinco) vezes, respectivamente.

\section{Exemplo 16: Move 3, ER4, Resumo 2}

Desenvolvemos uma pesquisa quantitativa e qualitativa, fundamentada nos estudos de Cagliari (1992) e Scarpa $(1999 ; 2005)[\ldots]$

Revista do GELNE, Natal/RN, Vol. 22 - Número 2: p. 39-51. 2020 
Exemplo 17: Move 3, ER4, Resumo 5

A pesquisa é qualitativa e foram usadas duas obras dos paradidáticos "Educando em Cordel" da autoria do cordelista $[\ldots]$

Nas introduções, os autores fizeram menção ao quadro teórico em que a pesquisa se baseou, com a finalidade de construir um lugar de destaque para a pesquisa e de afirmar que o estudo se seguiria sob a ótica de determinado autor, continuando assim uma tradição (Move 2, Passo 1D). Ainda na introdução, quando mencionados os procedimentos metodológicos, os autores se dedicaram a explanar de forma mais detalhada o que foi brevemente indicado no resumo. O Passo 4 (Resumindo a metodologia), no Move 3 (Ocupando o nicho) foi o único exemplo verificado no corpus da ocorrência das estratégias opcionais sugeridas por Swales (2004), com 04 (quatro) ocorrências.

\section{Exemplo 18: Move 3, ER4, Resumo 3}

Realizou-se uma pesquisa no Colégio Liceu Nóbrega de Artes e Ofícios da rede estadual de educação de Pernambuco, vinculado á Universidade Católica de Pernambuco.

\section{Exemplo 19: Move 3, Passo 4, Introdução 3}

Este trabalho é resultado de observações feitas no Colégio Estadual Liceu Nóbrega, localizado na cidade de do Refife/PE [...]

Foi investigado as atividades que fomentassem a leitura na instituição de ensino, tendo como foco a certeza de que leitura é algo fundamental [...]

Em uma relação comparativa quanto à similaridade e ao caráter das informações, descrever os resultados (ER1) é a estratégia única do Movimento 4 (Sintetizando os resultados), nos resumos. Verificamos também que apenas um autor delineou os resultados no resumo. Sabendo que os resumos acadêmicos "refletem uma sucinta descrição que compõe a maioria dos textos científicos: Introdução, Métodos, Resultado e Conclusões - IMRC” (OLIVEIRA, 2017, p. 156), podemos enxergar a falta da sintetização dos resultados nesse artigo especificamente como um fato atípico e que pode comprometer o caráter informativo do gênero resumo. As conclusões, igualmente, também são previstas, no resumo, apenas através da estratégia ER1 (Apresentando as conclusões), do Movimento 5, de mesmo nome.

\section{Exemplo 20: Move 4, ER1, Resumo 2}

Diante disso, os resultados sugerem que os alunos - embora ainda muito jovens- têm uma noção de quando adequar a escrita em situações de maior ou menor monitoramento (...)

\section{Exemplo 21: Move 5, ER1, Resumo 5}

(...) e concluímos que a preocupação principal destas pesquisas é referente à sintomatologia apresentada pela linguagem; quando não, pretendem traçar o caminho da prosódia até a clínica fonoaudiológica.

$\mathrm{Na}$ introdução, um caso isolado de apresentação das conclusões é representado pelo Exemplo 22, que a rigor não se enquadra em nenhum dos passos previstos no modelo CARS, uma vez que, ao contrário do que acontece nos resumos, as conclusões não são esperadas na introdução e sim nas considerações finais do artigo.

Exemplo 22: Move 3, passo não previsto, Introdução 3

Concluiu-se que, de fato, é extremamente necessário que as escolas conduzam o alunado para o mundo da leitura e ainda incorpore o próprio ato de ler ao dia a dia (...)

Aqui, percebe-se a ocorrência de um fato atípico, quando o autor expõe uma breve conclusão na introdução, com marcadores linguísticos bem evidentes. Uma vez que as conclusões 
foram omitidas no resumo, podemos entender que o autor achou necessário inseri-las na introdução, para não comprometer o caráter informativo global do texto.

\section{CONSIDERAÇÕES FINAIS}

Este estudo nos possibilitou investigar, a partir de Swales (1990; 2004) e Oliveira (2017), as estratégias retóricas que os graduandos utilizam para distribuir as informações entre resumos/abstracts e introduções de artigos acadêmicos, a eficácia com que os textos atingem o propósito comunicativo em determinadas áreas disciplinares e as estratégias retóricas que priorizam. Em nossas análises, constatamos que a maioria dos alunos seguiu os padrões retóricos esperados para o resumo e para a introdução, ainda que um autor não tenha realizado o Move $2 \mathrm{da}$ introdução (Estabelecendo um Nicho), o que tornou o texto menos informativo.

Em um olhar geral, pudemos observar que a relação de recorrência se deu, principalmente, através da ampliação, na introdução, do que já havia sido explanado de forma sucinta no resumo. E também, quando houve a omissão de determinadas informações, previstas pelos modelos retóricos, em determinada parte do texto, o autor se propôs a compensar tal omissão, inserindo-as na outra parte, como pôde ser observado nos exemplos 8 e 9 . A análise demostrou ainda que, quando houve situações atípicas, como ilustrado no exemplo 22, em que o autor inseriu a conclusão da pesquisa na introdução, tais situações foram entendidas como uma busca por compensar informações que foram omitidas, na tentativa de manter o padrão de continuidade entre o resumo e a introdução.

Quanto às estratégias retóricas mais recorrentes, constatou-se que, frequentemente, os autores fizeram generalizações acerca da temática da pesquisa, relataram os objetivos, indicaram os procedimentos metodológicos e resenharam pesquisas anteriores. Em contrapartida, eles raramente indicaram a estrutura do artigo, levantaram hipóteses ou apresentaram a justificativa da pesquisa. Mas isso não configura propriamente uma falha porque as subunidades retóricas tanto da introdução quando do resumo podem variar entre opcionais e obrigatórias, dependendo da importância que o autor confere às informações que pretende salientar. As informações foram mais bem distribuídas nos resumos e foram relativamente coerentes com o artigo na íntegra.

Acreditamos que este estudo foi consideravelmente relevante, uma vez que analisar os movimentos retóricos de um texto pertencente a um determinado gênero nos auxilia a compreender a essência do próprio gênero e o seu propósito social. Além disso, a relação entre resumo e introdução é um aspecto que ressalta a organização global do texto e a relação de continuidade entre as partes.

Assim, concluímos que os graduandos mantêm um certo padrão de coerência e continuidade entre o resumo e a introdução. Em relação aos modelos retóricos propostos por Swales $(1990,2004)$ e Oliveira (2017), os resumos apresentaram maior correspondência, com exceção de um artigo que não realizou o Movimento 2 (Introduzindo um propósito). A introdução, entretanto, foi mais priorizada no sentido de construir um lugar de destaque para a pesquisa a partir dos passos 1C (Levantando questionamentos) e 1D (Continuando uma tradição). Porém, o Movimento 2 (Estabelecendo um Nicho) não é confirmado com a mesma força dos demais movimentos na introdução.

Dessa forma, entendemos que os graduandos ainda buscam maneiras de produzir artigos científicos que atendam às exigências da comunidade acadêmica. Nessa busca, constatamos que seus textos, por um lado, mostram certas dificuldades em atingir esse objetivo, mas, por outro, já se ajustam pelo menos parcialmente às convenções estabelecidas.

\section{REFERÊNCIAS}

BEZERRA, Benedito G. Letramentos acadêmicos na perspectiva dos gêneros textuais. Fórum Linguístico, Florianópolis, v. 9, n. 4, p. 247-258, out./dez. 2012. 
BHATIA, Vijay K. Analysing genre: language use in professional settings. New York: Longman, 1993.

BIASI-RODRIGUES, Bernardete. Estratégias de condução de informações em resumos de dissertações. 1998. Tese (Doutorado em Linguística) - Universidade Federal de Santa Catarina, 1998.

BIASI-RODRIGUES, Bernardete; HEMAIS, Bárbara; ARAÚJO, Júlio C. Análise de gêneros na abordagem de Swales: princípios teóricos e metodológicos. In: BIASI-RODRIGUES, Bernardete; ARAÚJO, Júlio C.; SOUSA, Socorro Cláudia T. (Orgs.). Gêneros textuais e comunidades discursivas: um diálogo com John Swales. Belo Horizonte: Autêntica, 2009. p. 17-32.

BIASI-RODRIGUES, Bernardete; O gênero resumo: uma prática discursiva da comunidade. In: BIASI-RODRIGUES, Bernardete; ARAÚJO, Júlio C.; SOUSA, Socorro Cláudia T. (Orgs.).

Gêneros textuais e comunidades discursivas: um diálogo com John Swales. Belo Horizonte: Autêntica, 2009. p. 49-75.

FIAD, Raquel. A escrita na universidade. Revista da ABRALIN, n. especial, p. 357-369, 2011. FIAD, Raquel. Algumas considerações sobre os letramentos acadêmicos no contexto brasileiro. Pensares em Revista, v. 1, p. 23-34, 2015.

FISCHER, Adriana. A construção de letramentos na esfera acadêmica. 341f. Tese (Doutorado em Linguística) - Programa de Pós-Graduação em Linguística, Universidade Federal de Santa Catarina (UFSC), Florianópolis, 2007.

JOHNS, Ann M. Text, role and context: developing academic literacies. Cambridge: Cambridge University Press, 1997.

LEA, Mary R.; STREET, Brian V. Student writing in higher education: an academic literacies approach. Studies in higher education, v. 23, n. 2, p. 157-172, jun. 1998.

LEA, Mary R.; STREET, Brian V. The "academic literacies" model: theory and applications. Theory into practice, v. 45, n. 4, p. 368-377, 2006.

MARCUSCHI, Luiz Antônio. Letramento e oralidade no contexto das práticas sociais e eventos comunicativos. In: SIGNORINI, Inês (Org.). Investigando a relação oral/escrito e as teorias do letramento. Campinas/SP: Mercado de Letras, 2001. p. 23-50.

MOTTA-ROTH, Désirée; HENDGES, Graciela R. Produção Textual na Universidade. $1^{\circ}$ edição. São Paulo: Parábola Editorial, 2010.

OLIVEIRA, Giovane F. Os estudos dos Letramentos Acadêmicos no Brasil: influências, origens e perspectivas. DisSol, Pouso Alegre, v. 4, n. 5, p. 89-101, jan.-jun. 2017.

OLIVEIRA, John Hélio P. Análise de gêneros em contextos específicos: organização retórica e construção de sentidos no resumo de comunicação para eventos acadêmicos. 2017. Dissertação (Mestrado em Ciências da Linguagem) - Universidade Católica de Pernambuco, Recife, 2017. 
RITTI-DIAS, Fernanda G.; BEZERRA, Benedito G. Análise retórica de introduções de artigos científicos da área da saúde pública. Horizontes de Linguística Aplicada, Brasília, v. 12, n. 1, p. 163-182, 2013.

STREET, Brian V. Literacy in theory and practice. Cambridge: Cambridge University Press, 1984.

SWALES, John. M. Genre analysis: English in academic and research settings. Cambridge: Cambridge University Press, 1990.

SWALES, John M. Research genres: exploration and applications. Cambridge: Cambridge University Press, 2004.

Submetido em 12/11/2019

Aceito em 18/02/2020 